\title{
Implantação da Psicologia do Esporte no Município de Itajaí: Atuação do psicólogo junto a Fundação Municipal de Esporte e Lazer (FMEL)
}

\author{
Implementation of Sport Psychology in the Municipality of Itajaí: Performance of the psychologist \\ at the Municipal Foundation for Sport and Leisure (FMEL)
}

Simone Grazielle Capucci Rodrigues" $\bullet$

\author{
Servidora efetiva da Prefeitura Municipal de Itajaí, Itajaí, Santa Catarina, Brasil. Autor para correspondência. E-mail: \\ simone_rodrigues85@yahoo.com.br
}

\begin{abstract}
Resumo: Introdução: Tendo em vista a relevância da nova ciência do treinamento esportivo denominada Psicologia do Esporte que possui fundamental importância aos atletas no que se refere à otimização do desempenho esportivo, o presente projeto tem por objetivo a implantação da Psicologia do Esporte no Município de Itajaí junto a FMEL. Revisão: Trata-se de artigo de revisão bibliográfica com caráter descritivo que aponta que o aspecto biopsicossocial considera a saúde mental tão importante quanto à física no que se refere às emoções e estruturas mentais dos atletas. Discussão: Considera-se psicologia do esporte um estudo dos fatores comportamentais e emocionais que influenciam e são influenciados pelo desempenho esportivo. Considerações Finais: Observa-se que o papel do psicólogo na saúde psíquica de uma equipe desportiva desenvolve-se tendo como ponto de partida as emoções vivenciadas pelos esportistas em seu cotidiano.
\end{abstract}

Palavras-chave: Fundação Municipal de Esporte e Lazer, implantação, psicologia do esporte.

\begin{abstract}
Introduction: In view of the relevance of the new science of sports training called Sports Psychology that has fundamental importance to the athletes with regard to the optimization of sport performance, the present project aims to implement Sport Psychology in the Municipality of Itajai together the FMEL. Review: It is a bibliographical review article with a descriptive character that points out that the biopsychosocial aspect considers mental health as important as physics in relation to the emotions and mental structures of the athletes. Discussion: Sport psychology is considered a study of the behavioral and emotional factors that influence and are influenced by sports performance. Final considerations: It is observed that the psychologist's role in the psychic health of a sports team develops starting from the emotions experienced by the athletes in their daily lives.
\end{abstract}

Keywords: Municipal Sports and Leisure Foundation, implementation, sports psychology.

\section{Introdução}

Considerando a importância da atuação do psicólogo do esporte junto às equipes desportivas, principalmente as de alto rendimento, este artigo foi realizado no intuito de inserir o referido profissional na rede pública municipal de Itajaí, junto a Fundação Municipal de Esporte e Lazer (FMEL), instituição esta responsável pela gestão dos atletas que representam o município citado.

Para tanto, o mesmo contará com pesquisa bibliográfica como forma de justificar a inserção deste profissional junto à equipe multidisciplinar da FMEL, evidenciando o conceito e importância do psicólogo do esporte neste contexto, bem como, as etapas de implantação do trabalho e uma breve descrição das atividades realizadas pela instituição, nas quais o psicólogo pode contribuir.

No interior do presente artigo é possível observar de que forma se deu a evolução da Psicologia do Esporte no decorrer da história, bem como, a forma como se desenvolve na atualidade. Será possível perceber que o cuidado com a saúde mental dos atletas é tão importante como da saúde física, considerando o ser humano como único em ambos os aspectos, evidenciando que o acompanhamento nutricional, técnico e fisioterápico tornam-se incompletos quando os aspectos emocionais dos atletas, técnicos e equipes não são articulados.

Vale ressaltar que este artigo se trata apenas de revisão bibliográfica onde novos estudos abrangendo a pratica do psicólogo junto ao contexto esportivo se fazem necessárias para corroborar os dados. 


\section{Revisão}

\section{Aspectos históricos da psicologia do esporte}

A nova ciência de treinamento esportivo denominada psicologia do esporte se conceitua, de acordo com a American Psychological Association (APA), apud Ceppe (2014), como sendo "(a) um estudo dos fatores comportamentais que influenciam e são influenciados pela participação e desempenho no esporte, exercício e atividade física e (b) aplicação do conhecimento adquirido através deste estudo para a situação cotidiana (CEPPE, 2014)". Já nas palavras de Becker Junior, apud CEPPE (2014), presidente da Sociedade Brasileira de Psicologia do Esporte, tem-se esta conceituada como:

... uma disciplina chamada psicologia aplicada ao exercício e ao esporte que investiga as causas e os efeitos das ocorrências psíquicas que apresenta o ser humano antes, durante e após o exercício ou o esporte, sejam estes, de cunho educativo, recreativo, competitivo ou reabilitador (Becker Junior, 1999, apud CEPPE, 2014).

De acordo com Rubio (1999) a abrangência da psicologia do esporte nem sempre foi clara. Ainda assim, já no século XIX era possível encontrar estudos relacionados às questões psicofisiológicas no esporte. Porém, durante muito tempo este fenômeno foi tratado sem que houvesse uma definição exata de seu conceito e objetivo. Foi na década de 20 que importantes pesquisas de autores como e Griffith surgiram, sendo este último o fundador do primeiro laboratório de pesquisa aplicada ao esporte nos Estados Unidos.

Epiphanio (1999) salienta que já nesta época existia forte preocupação com o aperfeiçoamento técnico dos atletas, onde foi possível perceber o quanto as atitudes psicológicas de alguns atletas lhes favoreciam, o que incentivou o início dos estudos sobre os eventos psicológicos relacionados com as práticas esportivas.

Já no Brasil, CEPPE (2014) identifica que os primeiros registros oficiais tiveram seu início no ano de 1954, através do professor João Carvalhaes do Departamento de Árbitros da Federação Paulista de Futebol. Em seguida, três laboratórios de pesquisa do exercício foram criados em Porto Alegre, São Paulo e Rio de Janeiro, servindo de base para a evolução de várias disciplinas que envolvem as ciências do movimento humano, destacando-se dentre estas, a biomecânica, a fisiologia e a psicologia.

A prática da psicologia do esporte, composta por disciplinas como a antropologia, filosofia e sociologia do esporte, aponta para a necessidade da atuação pluridisciplinar ao ser incorporada junto às demais áreas de atuação no contexto, como a nutrição, fisiologia e biomecânica do esporte, tornando o nível técnico de atletas e equipes cada vez mais equilibrado, com ênfase especial à preparação emocional, tida como diferencial (Rubio, 1999).

Assim, a Psicologia do Esporte passou a ser vista como de suma importância nos debates sobre a dualidade mente-corpo enfatizando que ambos se integram formando uma totalidade inseparável, compreendendo a importante ligação do psiquismo com a saúde física (Epiphanio, 1999).

Desta forma, pode-se observar o surgimento e desenvolvimento de um campo de atuação denominado Psicologia do Esporte, que oferece importante contribuição para atividades físicas e de lazer (Rubio, 1999).

\section{A psicologia do esporte na contemporaneidade}

Antigamente mais focada nos aspectos exclusivamente biológicos, hoje a psicologia do esporte vem atuando nas mais variadas situações do contexto esportivo, tais como, motivação, personalidade, agressão e violência, liderança, dinâmicas de grupo e bem-estar dos atletas, integrando enfoques sociais, educacionais e clínicos (RUBBIO, 1999).

A psicologia do esporte ainda é considerada uma ciência nova, tendo sua atuação direcionada para a aplicação de técnicas junto aos atletas e comissão, na qual, Becker Junior (1999), apud CEPPE (2014), retrata que busca investigar e intervir na íntegra as variáveis que estejam influenciando as pessoas envolvidas com uma determinada prática esportiva e seu desempenho.

Rubio (1999) acrescenta que em 1983 o Centro Olímpico Americano expandiu os desdobramentos das práticas de atuação do psicólogo junto às práticas esportivas, onde, além da área de pesquisa e intervenção, propõe: a utilização de instrumentos de cunho exclusivo do psicólogo para a avaliação de potencial e deficiências dos atletas; o apoio não somente aos atletas, mas também a comissão técnica buscando lidar com as questões coletivas e individuais do grupo; a avaliação das estratégias e dos programas estabelecidos visando aprimoramento contínuo e otimizando rendimento; análise das condições do treinamento esportivo, realizando a intermediação entre atletas e comissão técnica e, por fim, as práticas de otimização do potencial de performance. 
Nas palavras de Fabiani (2007) pode-se perceber que é de fundamental importância que o atleta domine seus aspectos psicológicos para a competição através do estudo de suas particularidades psicológicas feito com o auxílio de um psicólogo do esporte. Desta forma, é possível alcançar a preparação necessária havendo equilíbrio entre a capacidade física e psicológica do atleta, proporcionando um melhor rendimento em quadra e, desta forma, também fora dela.

Isso porque o forte espírito competitivo e os conflitos na busca por vitória têm feito com que a psicologia do esporte venha sendo alvo de diversos debates, sempre tendo como foco a preocupação com o desempenho dos atletas tanto nos treinamentos como nas competições. Desta forma, procurando superar os limites físicos e mentais durante treinamentos e competições, sempre em busca de um objetivo marcado por rivalidade e confronto entre equipes (Fabiani, 2007).

Ao se falar em cuidar do corpo deve-se levar em consideração a importância de percebê-lo como um todo unificado, onde as emoções e estruturas mentais não devem ser postas de lado. Neste sentido, pode-se mencionar a abordagem bio-psico-social que aponta para os aspectos biológicos, psicológicos e sociais que envolvem todas as pessoas em diversos contextos. Portanto, quando se fala em psicologia do esporte trata-se de abordar as emoções vivenciadas pelos esportistas em seu cotidiano de trabalho (Weinberg, 2001 apud CEPPE, 2014).

Para tanto, Rubio (1999) faz referência também as práticas de dinâmicas de grupo, muito utilizadas na atuação da psicologia do esporte, visto que, os atletas e grupos vivem em seu cotidiano de forma limitada, ou seja, focada em treinamentos e competições, tendo uma interação de forma restritiva marcada por períodos de isolamento e concentração. Tal referência aponta para o impacto do desenvolvimento de uma personalidade comum, onde, ainda que mantenham seus traços individuais e peculiares, ganha contornos próprios no esporte, encontrando um perfil comum naquilo que se refere à conquista e ao êxito.

Estudos realizados em 1997 evidenciam que ainda que existam diversas diferenças individuais é possível detectar um perfil comum entre os atletas na busca pela autoconfiança, melhoria da concentração, preocupação positiva com o esporte, determinação e compromisso. Desta forma, o estágio atual do desenvolvimento da psicologia do esporte tem demonstrado importante preocupação em descrever características psicológicas entre os atletas, como a influência da personalidade no comportamento esportivo e as transformações desta personalidade a partir da interação grupal. Destaca-se ainda que o sucesso no esporte influencia decisivamente na saúde mental dos atletas, desenvolvendo uma auto percepção positiva e estratégias cognitivas de sucesso (Rubio, 1999).

Outros estudos realizados pela Federação Européia de Associações de Psicologia do Esporte - Fepsac (1996) citados por Becker Junior (1999) apud CEPPE (2014) apresentam que a psicologia do esporte trata das teorias psicológicas básicas, desenvolvimento e consequência do ajustamento psicológico das atividades voltadas ao esporte, tendo como foco as diferentes variáveis psicológicas do comportamento humano: afetiva, cognitiva, sensório-motora ou motivadora.

Rubio, (1999) destaca a definição da motivação como sendo uma direção e intensidade a um determinado esforço. No contexto esportivo trata-se tanto da busca individual de um determinado objetivo, como do grau de energia que uma pessoa despende para o cumprimento deste, afetando na seleção, intensidade e persistência do atleta, sendo estes aspectos decisivos na qualidade de suas performances.

Isso ocorre devido ao fato de cada atleta responder de maneira diferente a estímulos externos que podem ocorrer, antes, durante ou após uma competição, o que interfere significativamente nos rendimentos ao longo de uma competição, tornando essencial o desenvolvimento de habilidades em lidar também com o estresse e a ansiedade da pressão de uma competição (Fabiani, 2007).

O estresse geralmente ocorre quando se percebe no ambiente em que se está inserido que a ocorrência de um fracasso trará consequências significativas, fazendo com que os níveis de ansiedade se elevem. Deste modo percebe-se que, no contexto esportivo, a ansiedade e o estresse se apresentam sempre interligados (Rubio, 1999).

Silveira (2009) aponta que muitas são as implicações que giram em torno de uma competição, onde, dependendo das situações em que esta ocorra, muitos problemas não apenas de ordem física, mas principalmente psicológica podem surgir. A própria situação de competir já é uma situação de extrema ansiedade tanto para os atletas como para seus dirigentes, técnicos e até mesmo para os torcedores.

A ansiedade entre os atletas pode ser observada tanto antes de uma competição como durante e após a mesma, mas de acordo com Fabiani (2007) a pior ansiedade é a que antecede a competição, pois esta se relaciona e influencia diretamente em seu desempenho. Sua origem se dá devido a inúmeras variáveis e fenômenos psicológicos que podem ser de natureza cognitiva, possuir aspectos motivacionais ou estar diretamente ligada a fatores ambientais. 
Observa-se que neste aspecto, a prática do psicólogo do esporte se relaciona com o manejo da ansiedade ou excitação antes e durante as competições, auxiliando no desenvolvimento de estratégias positivas de controle dessas situações, bem como, do manejo do estresse, visto que, estes estados são facilmente observados em qualquer situação de competitividade (Rubio, 1999).

Por este motivo diversos treinadores têm se preocupado com o nível de ansiedade de seus atletas, reconhecendo que seus desequilíbrios podem provocar apreensão e descontrole nocivos às competições. Nestes casos a ansiedade pode se tornar debilitante, fazendo com que os atletas se sintam ameaçados ou incapazes de desempenharem sua atividade (Silveira, 2009).

Vale ressaltar que a ansiedade e o estresse podem ser de suma importância na preparação psicológica do atleta, podendo trazer efeitos positivos durante uma competição ou treinamento. É o que aponta Fabiani (2007) trazendo que o estresse é uma resposta adaptativa do organismo frente a uma situação de tensão, podendo se tornar facilitador diante do desafio.

Diante disso Rubio (1999) alerta para a importância de se distinguir as situações em que a ansiedade aparece na forma de disposição e ânimo, das situações em que esta aparece como um traço de personalidade, podendo, neste caso, trazer efeitos negativos para o atleta.

Silveira (2009) também aponta que o estresse e a ansiedade até certo nível podem ser considerados benéficos, lembrando que estes fatores, se bem nivelados, contribuem para o despertar da competitividade necessária para enfrentar a tensão oriunda do estado de pressão durante uma competição. Diante disso se faz necessário avaliar se a situação é de preocupação intensa, o que pode ser prejudicial, ou se apenas denota um quadro de excitação que auxilia no preparo para enfrentar a competição.

Desta forma observa-se então que "a psicologia do esporte é o estudo científico de pessoas e seus comportamentos em contextos esportivos e de exercícios e aplicações práticas de tal conhecimento" (Gil, 1986 apud CEPPE, 2014). Princípios e diretrizes são então identificados para que adultos e crianças se beneficiem de atividades esportivas. As falas tão comumente observadas pelos atletas "temos que nos preparar psicologicamente para esta partida" (Becker Junior, 1998, apud CEPPE, 2014) ou mesmo "fisicamente o time está bem, mas psicologicamente vem passando por dificuldades" (Becker Junior, 1998, apud CEPPE, 2014) demonstram que as necessidades psicológicas esportivas são incontestáveis. Sendo assim, a psicologia do esporte busca compreender melhor as demandas que envolvem suas atividades dando assistência aos atletas com consequente crescimento pleno e equilibrado (Becker Junior, 1986 apud CEPPE, 2014).

Para tanto, o autor acima citado compreende que o psicólogo esportivo deve, por norma de atuação, respeitar e seguir algumas etapas que compreendem o processo de implantação de seu programa de Psicologia Esportiva descritas a seguir.

\section{Etapas de implantação da psicologia do esporte}

De acordo com CEPPE (2014) as etapas de implantação do serviço de Psicologia do Esporte devem abranger:

Informação: Momento em que todos os integrantes envolvidos com o grupo esportivo recebem informações acerca de como funciona o programa de psicologia do esporte e fornecem ao psicólogo informações básicas sobre o funcionamento da instituição e do grupo no qual o psicólogo realizará seu trabalho.

Pré-programa: estruturado pelo psicólogo que utiliza como base as informações recebidas de modo que toda a equipe possa contribuir com a implantação do mesmo.

Programa: A cada início de um novo trabalho verifica-se a necessidade de observação inicial a respeito do contexto no qual o programa será desenvolvido, enfocando, tanto os indivíduos e suas peculiaridades, como a formação dos grupos e os processos de interação que ocorrem entre eles. Neste momento deve ser observado também o nível de ansiedade em que se encontram os atletas, seu comportamento e estado emocional em treinamentos e competições, nível de agressividade (externa e interna), nível de atenção (concentrada e dispersa), depressão, motivação e outros aspectos que auxiliam o psicólogo a conhecer o contexto desportivo no qual está sendo inserido.

Vale lembrar que, somente após o levantamento de todos esses aspectos é que o psicólogo se encontrará apto a passar para a fase de intervenção frente às necessidades levantadas. A utilização destas normas com respeito, simplicidade e ética será fator decisivo no sucesso da aplicação do presente projeto. (CEPPE, 2014). 


\section{Aspectos éticos na psicologia do esporte}

Primeiramente, para conceituar a palavra ética, Winterstein (2004) aponta esta como sendo algo que direciona o comportamento das pessoas de forma a aprová-las ou censurá-las, analisando a maneira de agir de cada um no exercício de sua cidadania.

Com relação à ética na psicologia do esporte Vieira et al. (2010) traz o conceito da Association for the Advancement of Applied Sport Psychology que enfatiza questões como “...competência, integridade, responsabilidade pessoal e científica, respeito pelos direitos e pela dignidade das pessoas, preocupação com o bem-estar dos outros e responsabilidade social" (Vieira, 2010).

Tais aspectos, como o sigilo, profissionalismo na relação terapêutica, honestidade perante os objetivos do seu trabalho, atualização e aperfeiçoamento profissional, o respeito à pessoa atendida, entre outros, são facilmente conhecidos e apontados por qualquer profissional da área. Porém, pouco se fala sobre a necessidade da ética profissional no uso de técnicas psicologias que coloquem em questão a liberdade de decisão dos atletas, que nem sempre encontram espaço para aceitar ou refutar o uso das técnicas orientadas, principalmente quando se trata de equipe que atua sob autoritarismos e contratos rigorosos (Winterstein, 2004).

Neste sentido, o autor chama atenção para a necessidade de uma discussão crítica a este respeito, observando que não basta submeterem projetos a membros de comissão de ética quando se tem, de um lado, comissões apenas pautadas em interesses corporativistas e, de outro, profissionais que simplesmente buscam se inserir no mercado. Sendo assim, deve-se buscar obter o consentimento e a participação ativa do atleta perante as técnicas psicológicas utilizadas, lançando mão de uma postura quase "milagrosa" que profissionais vem adotando, assumindo para si próprios toda a responsabilidade de sucesso dos atletas de sua equipe como se apenas os aspectos psicológicos fossem decisivos em uma vitória.

\section{A Fundação Municipal De Esporte e Lazer De Itajaí}

De acordo com o site oficial do Município de Itajaí, através de informações fornecidas pela Secretaria Municipal de Comunicação (SECOM, 2017) 20, a Fundação Municipal de Esporte e Lazer de Itajaí foi instituída através da Lei ${ }^{\circ} 2.438$ de 07 de março de 1989 como um órgão governamental vinculado à Prefeitura de Itajaí. Objetiva implantar políticas públicas que desenvolvam o esporte na cidade, utilizar as práticas esportivas como estratégia, alcançando o desenvolvimento das pessoas e enfatizar políticas de recreação, lazer e iniciação esportiva, favorecendo, desta forma, crianças e adolescentes, em especial atenção às comunidades carentes. Com vistas para seu desenvolvimento psicomotor e inclusão social democratiza e desperta o interesse da sociedade e facilita o acesso.

Para tanto, atualmente conta com programas como: Segundo tempo, Itajaí Ativo, Escolhinhas Esportivas, Esporte de Rendimento, Paradesportivo, e ainda, para a Terceira Idade.

Além disso, desenvolve também programas como Lei Municipal de Incentivo ao Esporte, que busca a formação esportiva de base e manutenção, realização de eventos esportivos, aquisição de materiais esportivos, de lazer e recreação e implementos paradesportivos, investimento em cursos de capacitação profissional e eventos científicos, tais como, fóruns, seminários, conferências e congressos. O programa Bolsa Atleta oferece incentivo para jovens no desenvolvimento da pratica esportiva, mediante a concessão de bolsas remuneradas destinada a técnicos, auxiliares técnicos, atletas, paratletas e guias. No que se refere ao público da terceira idade, destaca-se, entre outras atividades o Festival de Handebol destinado a atletas com mais de 60 anos.

\section{Discussão}

American Psychological Association (APA), apud Ceppe (2014), conceitua Psicologia do Esporte como sendo "(a) um estudo dos fatores comportamentais que influenciam e são influenciados pela participação e desempenho no esporte, exercício e atividade física e (b) aplicação do conhecimento adquirido através deste estudo para a situação cotidiana (CEPPE,2014)”.

Já nas palavras de Benno Becker Junior, apud Ceppe (2014), presidente da Sociedade Brasileira de Psicologia do Esporte, tem-se esta conceituada como:

“... uma disciplina chamada psicologia aplicada ao exercício e ao esporte que investiga as causas e os efeitos das ocorrências psíquicas que apresenta o ser humano antes, durante e após o exercício ou o esporte, sejam estes, de cunho educativo, recreativo, competitivo ou reabilitador" (Becker Junior, 1999, p. 17 apud CEPPE 2014). 
De acordo com Rubio (1999) a abrangência da psicologia do esporte nem sempre foi clara. Ainda assim, já no século XIX era possível encontrar estudos relacionados às questões psicofisiológicas no esporte. Porém, durante muito tempo este fenômeno foi tratado sem que houvesse uma definição exata de seu conceito e objetivo. Foi na década de 20 que importantes pesquisas de autores como e Griffith surgiram, sendo este último o fundador do primeiro laboratório de pesquisa aplicada ao esporte nos Estados Unidos.

Epiphanio (1999) salienta que já nesta época existia forte preocupação com o aperfeiçoamento técnico dos atletas, onde foi possível perceber o quanto as atitudes psicológicas de alguns atletas lhes favoreciam, o que incentivou o início dos estudos sobre os eventos psicológicos relacionados com as práticas esportivas. Assim, a Psicologia do Esporte passou a ser vista como de suma importância nos debates sobre a dualidade mentecorpo enfatizando que ambos se integram formando uma totalidade inseparável, compreendendo a importante ligação do psiquismo com a saúde física.

A psicologia do esporte ainda é considerada uma ciência nova, tendo sua atuação direcionada para a aplicação de técnicas junto aos atletas e comissão, na qual, Becker Junior (1999), apud CEPPE (2014), retrata que busca investigar e intervir na íntegra as variáveis que estejam influenciando as pessoas envolvidas com uma determinada prática esportiva e seu desempenho.

Nas palavras de Fabiani (2007) pode-se perceber que é de fundamental importância que o atleta domine seus aspectos psicológicos para a competição através do estudo de suas particularidades psicológicas feito com o auxílio de um psicólogo do esporte. Desta forma, é possível alcançar a preparação necessária havendo equilíbrio entre a capacidade física e psicológica do atleta, proporcionando um melhor rendimento em quadra e, desta forma, também fora dela.

Desta forma observa-se então que "a psicologia do esporte é o estudo científico de pessoas e seus comportamentos em contextos esportivos e de exercícios e aplicações práticas de tal conhecimento" (GIL, 1986 apud CEPPE, 2014). Sendo assim, a psicologia do esporte busca compreender melhor as demandas que envolvem suas atividades dando assistência aos atletas com consequente crescimento pleno e equilibrado (Becker Junior, 1986 apud CEPPE, 2014).

\section{Considerações finais}

Através da revisão bibliográfica buscou-se analisar o impacto da psicologia do esporte junto ao cotidiano de atletas, sendo possível perceber a importância de sua contribuição junto a FMEL.

Desta forma, foi possível compreender que a psicologia do esporte aponta para decisiva otimização no desempenho das equipes ao atuar sobre aspectos das personalidades individuais e grupais dos atletas, seus aspectos motivacionais, liderança e manejo da ansiedade e estresse.

Através de técnicas que priorizam atendimentos em grupo é possível também oportunizar momentos de integração e relaxamento, fortalecer a coesão grupal e trabalhar demandas vivenciadas no cotidiano dos atletas e apontadas como necessárias por estes, pela comissão técnica ou demais profissionais envolvidos.

A psicologia do esporte é uma área que se encontra em fase de expansão, apesar dos avanços que já obteve ao longo da história, sendo ainda necessário o desenvolvimento de diversos estudos teóricos e práticos, bem como, a construção de ferramentas específicas para a atuação profissional nesta área.

Vale ressaltar que novos estudos se fazem necessário abrangendo os aspectos práticos do psicólogo junto ao contexto esportivo a fim de corroborar os dados apresentados.

\section{Referências}

Consultoria Estudo e Pesquisa Psicologia do Esporte [CEPPE]. 2014. Disponível em: http://www.ceppe.com.br/psicologia-do-esporte/. Acesso em: 4 mar. 2019

Epiphanio, E. H. 1999. Psicologia do Esporte: apropriando a desapropriação. Psicologia, Ciência e Profissão, 19(3), 70-73.

Fabiani, M. T. 2007. Psicologia do Esporte: A Ansiedade e o Estresse Pré-Competitivo. Disponível em: http://www.pucpr.edu.br/eventos/educere/educere2008/anais/pdf/182_454.pdf. Acesso em 10 jan. 2019

Rubio, K. 1999. A psicologia do esporte: histórico e áreas de atuação e pesquisa. Psicologia, Ciência e Profissão, 19(3), 60-69.

Secretaria Municipal de Comunicação [SECOM]. 2017. Município de Itajaí. Disponível em: www.itajai.sc.gov.br. Acesso em: 4 mar. 2019. 
Silveira, R. O. Análise dos Níveis de Ansiedade Pré-Competitiva de Atletas de Futsal. Trabalho de conclusão de curso (Universidade Federal de Minas Gerais). Belo Horizonte, MG: UFMG.

Vieira, L. F., Vissoci, J. R. N., Oliveira, L. P. D., \& Vieira, J. L. L. 2010. Psicologia do esporte: uma área emergente da psicologia. Psicologia em Estudo, 15(2), 391-399.

Winterstein, P. J. 2004. Ética no Esporte e na Psicologia do Esporte: reencontrando caminhos. Revista Digital, Buenos Aires, 76.

\section{Minicurrículo}

Simone Grazielle Capucci Rodrigues. Psicóloga formada pela Universidade do Vale do Itajaí e pós-graduada em Psicologia do Esporte pela Faculdade Dom Alberto do RS. Servidora efetiva do quadro de servidores da Prefeitura Municipal de Itajaí, atualmente lotada na Fundação Municipal de Esporte e Lazer (FMEL) após aprovação do referido projeto.

Como citar: Rodrigues, S.G.C. 2020. Implantação da Psicologia do Esporte no Município de Itajaí: Atuação do psicólogo junto a Fundação Municipal de Esporte e Lazer (FMEL). Pubsaúde, 4, a057. DOI: https://dx.doi.org/10.31533/pubsaude4.a057

Recebido: 29 jul. 2020.

Revisado e aceito: 2 ago. 2020 .

Conflito de interesse: os autores declaram, em relação aos produtos e companhias descritos nesse artigo, não ter interesses associativos, comerciais, de propriedade ou financeiros que representem conflito de interesse.

Licenciamento: Este artigo é publicado na modalidade Acesso Aberto sob a licença Creative Commons Atribuição 4.0 (CC-BY 4.0). 